University of Nebraska - Lincoln

DigitalCommons@University of Nebraska - Lincoln

Faculty Publications, Department of Child, Youth, and Family Studies

Child, Youth, and Family Studies, Department of

2013

\title{
The Adjustment of Asian American Families to the U.S. Context: The Ecology of Strengths and Stress
}

\author{
Yan Ruth Xia \\ University of Nebraska-Lincoln, rxia2@unl.edu \\ Kieu Anh Do \\ University of Nebraska-Lincoln, Ando111@yahoo.com \\ Xiaolin Xie \\ Northern Illinois University, xialinx@niu.edu
}

Follow this and additional works at: https://digitalcommons.unl.edu/famconfacpub

Part of the Demography, Population, and Ecology Commons, Family, Life Course, and Society

Commons, Place and Environment Commons, and the Race and Ethnicity Commons

Xia, Yan Ruth; Do, Kieu Anh; and Xie, Xiaolin, "The Adjustment of Asian American Families to the U.S. Context: The Ecology of Strengths and Stress" (2013). Faculty Publications, Department of Child, Youth, and Family Studies. 80.

https://digitalcommons.unl.edu/famconfacpub/80

This Article is brought to you for free and open access by the Child, Youth, and Family Studies, Department of at DigitalCommons@University of Nebraska - Lincoln. It has been accepted for inclusion in Faculty Publications, Department of Child, Youth, and Family Studies by an authorized administrator of DigitalCommons@University of Nebraska - Lincoln. 


\title{
The Adjustment of Asian American Families to the U.S. Context:The Ecology of Strengths and Stress
}

\author{
Yan Ruth Xia,' Kieu Anh Do,' and Xiaolin Xie ${ }^{2}$ \\ I. Department of Child, Youth, and Family Studies, University of Nebraska-Lincoln, Lincoln, NE, USA \\ emails rxia2@unl.edu \&Andol II@yahoo.com \\ 2. School of Family, Consumer, and Nutrition Studies, Northern Illinois University, DeKalb, IL 60 I I5, USA \\ email xialinx@niu.edu
}

\section{Demography, History, and Culture}

Asian Americans are represented by estimated 28 subgroups and are unique and diverse in their own languages, cultures, and socioeconomic backgrounds (Ishii-Kuntz, 2000). In 2000, there were approximately 11.9 million Asian Americans in the United States (U.S. Census Bureau, 2000). In 2008, the number increased to 15.5 million, comprising more than 4.6 of the total US population (U.S. Census Bureau, 2009b) and this number was projected to increase to 40.6 million by 2050 (U.S. Census Bureau, 2008). According to data from the U.S. Census Bureau (2000), the most notable post-1965 change was the rapid population growth of Asian Americans, from less than 1.5 million in 1970 to 11.9 million in 2000. The net increase of Asian American population from 2000 to 2009 is over 3.4 million (U.S. Census Bureau, 2011). This figure is currently growing, but does not account for individuals with mixed ancestries, such as Asian and Hispanic, Asian and Black, or Asian and White. As a whole, Asian Americans are quite diverse in terms of nationalities, languages, ethnicities, and cultural traditions. The three largest Asian American populations in the United States, accounting for about $60 \%$ of the total Asian population, are
Chinese (over 2.8 million), Asian Indian (over 2.2 million), and Filipino (over 2.1 million) (U.S. Census Bureau, 2004). The three smallest Asian American populations in the United States, comprising only $0.7 \%$ of the total Asian population, include Sri Lankan (22,339), Malaysian (11,548), and Bangladeshi $(50,473)$ (U.S. Census Bureau).

In examining the Asian American population by region, the majority (40\%) reside in the West, with similar numbers living in the Northeast and Southern regions, $21.2 \%$ and $21.1 \%$, respectively (U.S. Census Bureau, 2008). A smaller percentage (11.7\%) of Asian Americans live in the Midwest region (U.S. Census Bureau). Hawaii (38.5\%), California $(12.4 \%)$, and New Jersey $(7.6 \%)$ rank as the three most concentrated Asian American populations when compared to the total state populations (U.S. Census Bureau).

Within the private sphere of the home, data from the 2008 American Community Survey (ACS) indicated that there were approximately 3.1 million Asian American family households, $81.4 \%$ of which consisted of married couples, $12.1 \%$ of single female-headed households, and about $6.5 \%$ of single male-headed households (U.S. Census Bureau). For the most part, Asian Americans are highly educated, with $49.4 \%$ holding a Bachelor's 
degree or higher and only $14.6 \%$ having less than a high school education. Occupationally, $47.1 \%$ of Asian Americans hold managerial, professional, or related positions. This chapter will focus on Asian American families that migrated to the United States in the last 3 decades. Myths about Asian American families will be examined, along with the ecology of stress that influences family dynamics, and their family strengths and resiliencies.

\section{Myths About Asian American Families}

Asian American families are far from what the media has often depicted as the Model Minority because they have their fair share of challenges and stresses. At times, these challenges and stresses are not well recognized, and thus, do not receive immediate or sufficient attention. Below are some myths pertaining to Asian American families.

\section{Myth I:Asian American Students Are Model Students: Good Grades, Respectful, and Trouble-Free}

Students from Asian America families are supposed to get straight A's in school; they must be very respectful to teachers and parents, they must be drug-free or trouble-free; their parents must be well educated and have good salaries; their families must live comfortably. This stereotypical image of the Model Minority hurts Asian American communities. For example, this stereotype may contribute to Asian students not being eligible for some scholarships or financial assistance that is available to minority students. "Politically, this idealized picture of Asian families has been used to criticize everything from the woes of other minorities and their dependence on big government to the consequences of our country's departure from traditional family roles" (Lee \& Zhan, 1998, p. 132). As a result, Asian American individuals may be alienated from peers or coworkers (Leong \& Grand, 2008; Lo, 2010; Tang, 2008) and their issues may not receive enough attention or warrant the same type of social and community support. As a result, their relationship with these groups in the social context may be strained.

\section{Myth 2:Asian American Families Earn More Money Than Other Ethnic Families}

According to the ACS, conducted by the U.S. Census Bureau's (2009a), the median income of Asian households was $\$ 68,780$, which is higher than Whites $(\$ 53,131)$, Blacks $(\$ 33,463)$, and Hispanics $(\$ 39,923)$. However, there are several reasons contributing to this high income when we take into account the characteristics of Asian households. For example, Asian families tend to be intergenerational, with many individuals, including grandparents, parents, children, and sometimes even unmarried aunts or uncles. Data from the ACS (U.S. Census Bureau, 2009a) indicated that $11.4 \%$ of Asian households consisted of other relatives, whereas only $5.3 \%$ of White households were so. More specifically, 5.9\% were in a household with grandchildren compared to $2.9 \%$ of Whites. In addition, due to the collectivistic nature of Asian culture, these family members often pool their income together. Therefore, anybody who can work is encouraged to contribute to the household income, and family financial resources are shared. As such, the family or household income appears to be high, but the average resources per person may be limited.

Chan (1991), a leading researcher in Asian American studies, reexamined returns on education discussed by sociologists. Returns on educations referred to additional dollars earned for each additional year of education obtained after high school. Asian Americans were disadvantaged when their investment in education was taken into account. The additional income earned by investing each additional year in college was estimated at $\$ 320$ and $\$ 438$ for Chinese and Japanese Americans, respectively, as compared to $\$ 522$ for Whites (Varma, 2004). They have to complete more years of education in order to reach the same income level. 


\section{Myth 3:All Asian American Families Are Sailing off Smoothly After They Migrate to the United States}

Asian Americans are more diverse than homogeneous. They or their ancestors came from different ethnic groups, for various reasons, and with unique cultural heritages. For example, a vast number of Asian Americans who migrated from Southeast Asia (e.g., Vietnam, Laos, Cambodia) in the last 30 years left their countries involuntarily as refugees while those from Japan, China, and India came voluntarily to pursue an advanced degree and promising careers. Most refugee immigrants were neither prepared psychologically, nor were equipped with English language skills. They were faced with many challenges in adjusting to their lives in the United States. They do, however, exhibit resiliency and strengths that help overcome adversity. For example, Vietnamese Americans living in eastern New Orleans before Katrina drew strengths from their culture and history to rebuild their community (Leong, Airriess, Li, Chen, \& Keith, 2007). By early 2007, more than $90 \%$ of former Vietnamese American residents had returned to eastern New Orleans.

\section{The Ecology of Stress}

Asian American families face a multitude of stressors and challenges. Some are general life stressors, while others are more unique to Asian Americans as an ethnic and cultural group. The type of stress and challenges, however, also varies across ethnicity and culture, country of origin, acculturation level, education, language skills, migration history, social class, and length of residency in the United States. These contextual sources of stress and challenge originate both at the broader societal level and within individual families. They directly or indirectly influence parent-child relationships, couple's relationships, power structures, and gender roles.

For example, results from the Mental Health America Attitudinal Survey (2006) revealed that $34 \%$ of the Asian Americans sampled indicated feeling stressed from their relationships with others, family relationships, and employment, while nearly $42 \%$ reported stress relating to finances. More specifically, Blair (2000) conducted a study with a random sample of 124 Cambodian adults in Utah, who have been in the United States an average of 8.1 years. The participants rated 14 stressors on average as being "very stressful" within their first year in the United States. The top four stressors included: (a) A lack of adequate English skills (77\%); (b) thoughts about family members who had been left behind (63\%); (c) transportation problems (62\%); and (d) thoughts about people they had known who were killed in Cambodia (60\%).

The researcher also assessed stressors during the past year, and participants identified an average of 5.2 "very stressful" issues, with the top four being: (a) worries about the future in the United States $(27 \%)$; (b) health worries (26\%); (c) worries about family left behind in Cambodia (24\%); and (d) worries about not having enough money (23\%) (Blair, 2000). These findings illustrate three important patterns concerning the type and level of stress experienced by Cambodian refugees in particular and Asian American immigrant families in general. First, these families tend to have "very stressful" feelings about basic survival and adaptation in the beginning phase of their resettlement in the United States. Basic language skills and the ability to get from one place to another are essential for daily living in the host country. Second, the types and level of stress in general tend to diminish as the families acculturate and find ways to meet their basic needs. In the latter phase of their resettlement, Asian immigrant and refugee families tend to worry about their future in the United States, and their health and well-being. The third pattern demonstrates the strong kinship system and family interdependency among Asian Americans. Although migration, time, and distance impeded family relationships, Cambodian refugees continued to worry about family members they have left behind in their country of origin. Overall, these stressors can have detrimental effects on Asian immigrants and refugees, with Blair (2000) concluding that these stressors contributed to substantial amounts of depression among Cambodian refugees. 


\section{Racism, Prejudice, and Discrimination}

One of the more prevalent issues that is sometimes difficult to label and eliminate is the issue of racism, prejudice, and discrimination that Asian American and other minority groups experienced in both a historical and contemporary context. For instance, in 1882 the Chinese Exclusion Act banned immigration from China, and in 1907 and 1908, similar restrictions were placed on Japanese and Korean immigrants through the Gentlemen's Agreement (U.S. DHHS, 2000). A decade later, The Immigration Act of 1917 limited the entry of Asian Indians (U.S. DHHS). Asian Americans also were denied the rights to citizenship, suffrage, and due process under the law (Zia, 2000). For example, in 1923 in United States v. Bhagat Singh Thind, the Supreme Court ruled that Asian Indians were ineligible for citizenship (Gee, Spencer, Chen, Yip, \& Takeuchi, 2007). During World War II, Japanese Americans were put in internment camps and were treated as enemies (Zia, 2000).

In the everyday context, Yoo, Gee, and Takeuchi (2009) conducted a telephone survey and found that $7 \%$ of Asian Americans (N=888; 376 Chinese, 245 Vietnamese, 267 Korean Americans) in their sample reported experiencing racial discrimination and $12 \%$ reported language discrimination. As expected, recent Asian immigrants, or those residing in the United States for less than 10 years, indicated the highest level of racial (9\%) and language discrimination (19\%) (Yoo et al.). While U.S.-born Asian Americans experienced the least language discrimination $(0 \%)$, they still encounter racial discrimination (4\%) (Yoo et al.). Asian Americans continue to face employment and housing discrimination (Turner, Ross, Bednarz, Herbig, \& Lee, 2003) as well as more severe issues, including hate crimes and racial profiling by law enforcement (Gee, Spencer, et al., 2007; Zia, 2000).

Although some Asian American groups, such as Japanese, Chinese, and Korean Americans, have been in the United States for many generations, they are still considered foreigners due to their physical characteristics. According to the Surgeon General, racial discrimination is a critical risk factor for mental disorders and other psychological issues (U.S. DHHS, 2000). For example, racial discrimination is significantly correlated with depressive symptoms in Filipino, Vietnamese, Laotian, and Cambodian eighth and ninth graders surveyed in California and Florida (Rumbaut, 1994). Similarly, racial discrimination is associated with greater risk for depressive and anxiety disorder in Vietnamese, Filipino, Chinese, Asian Indians, Japanese, Korean, and Pacific Islanders (Gee, Spencer, et al., 2007). In addition, unfair treatment related to discrimination is associated with increased prescription and illicit drug use as well as alcohol dependency in Filipino Americans (Gee, Delva, \& Takeuchi, 2007). Even after controlling for age, sex, education, family income, health insurance, primary language, nativity status, and ethnicity, both racial and language discrimination were significantly correlated with increased chronic health conditions in Asian Americans (Yoo et al., 2009).

\section{Acculturative Stress}

New Asian immigrant and refugee families face the stress relating to their migration experience, and the ongoing adjustments to the new culture and new life. The uprooting process of immigration is challenging, because it fractures the existing social network. The family also struggle to acquire a new language and acculturate to the new environment. Family problems and tension are more likely to erupt due to these changes.

Specifically, refugee families, who came from war-torn nations and refugee camps, may have to deal with post-traumatic and psychological issues relating to their experiences. These effects may last for years, even after they have settled in the host country. For instance, a study conducted by Hinton, Rasmussen, Leakhena, Pollack, and Good (2009), with 143 Cambodian refugee patients at a psychiatric clinic in Massachusetts, highlights these important issues. The refugees in the sample had survived the Pol Pot genocide (1975-1979), in which more than 1.7 million Cambodians were executed or died of starva- 
tion (Hinton et al.). In examining the family level of anger, the researchers found that almost half $(48 \%)$ of the participants reported becoming angry with a family member in the last month, and about $10 \%$ were specifically angry with a spouse (Hinton et al.). The reasons varied from personal relationship issues (infidelity, 29\%) to employment and financial stress (not having a paying job, 22\%) (Hinton et al.). Moreover, about 45\% of the participants indicated experiencing anger toward their children $(\mathrm{N}=64)$, and the reasons ranged from a child acting disrespectfully (30\%) (e.g., yelling at a parent) to a child staying past curfew (30\%). Interestingly, 68\% had trauma recalls during these anger episodes, and half had flashbacks (52\%) (Hinton et al.). These findings highlight the interesting dynamic between psychological and family issues.

The acculturation gaps within Asian American families may also be a source of conflict (Sue \& Sue, 2008). Often times, children in immigrant and refugee families learn the language and acculturate faster than their parents. The differential rates of acculturation sometimes make the parents more dependent on their children for help in terms of language translation and other social interactions. The role reversal sometimes affects the quality of the parent-child relationship (Yee, DeBarysche, Yuen, Kim, \& McCubbins, 2006). In conjunction with acculturation, children may adopt American values and behaviors that may conflict with those of their parents. Parents and elders may see it as a sign of disrespect due to differing styles of communication and behaviors. Children may develop individualistic goals that are divergent from their collectivistic family orientation (Costigan \& Dokis, 2006; Sue \& Sue, 2008).

Migration and acculturation are multifaceted events involving changes at the social, emotional, cultural, and economic levels. Acculturation is the process whereby the values, attitudes, behaviors, and relationships of persons from one culture are modified as a result of contact with a different culture (Berry, 2001; Moyerman \& Foreman, 1992). Specifically, the changes may mean that new immigrants take on different jobs, de- velop a new relationship with spouse and children, and acquire new parenting skills (Chung \& Bemak, 2006). As such, stress often results from these changes which are an inherent part of immigration experiences. (Sodowsky, Kwan, \& Pannu, 1995). Acculturative stress often entails three aspects: (1) life-long duration, (2) pervasiveness, and (3) intensity (Smart \& Smart, 1995). Acculturative stress, however, can serve as a motivator for positive change within the immigrant families and it is not always negative (Bush, Bohon, \& Kim, 2009).

\section{Financial Stress}

The removal of the family from its extended social network also leads to a loss of the resources provided by that network. For old and new immigrants, economic and financial strain may cause family tension. In a study of Chinese adolescents and parents, Mistry, Benner, Tan, and Kim (2009) found that there are evidence of some family strain reported by Chinese parents and their adolescents, specifically involving arguments over money. In addition, these conflicts were associated with adolescents' psychological and academic functioning, in that youths who perceived greater family economic strain experienced greater emotional distress and depressive symptoms, as well as lower educational outcomes. Therefore, financial strains within the home have important implications for child and youth development.

Family obligations and filial piety are strong values in the Asian American family and collectivistic cultural values enforce the importance of sharing resources. According to the American Association of Retired Persons (2001), Asians (42\%) were more likely to assist in caring for or financially supporting parents, in-laws, or other older relatives than Whites (19\%), Blacks (28\%), or Hispanics $(34 \%)$. Particularly for new immigrants, underemployment or unemployment not only produces financial hardship, it could also engender feelings of worthlessness and failure to fulfill family obligations. Both old and new immi- 
grants sometimes have to support not only their primary family in the United States, but also extended families in their country of origin. For example, "A key aspect of Filipino financial practice is the remittance of funds which operates through the extended family" (Woelz-Stirling, Manderson, Kelaher, \& Gordon, 2000, p. 7). These financial resources go toward the education of and to support children they have left behind, younger siblings or extended family members, as well as covering family medical and other expenses (Woelz-Stirling et al.). Remitting money may produce a financial strain on the Asian American family, and it may also be a potential source of marital distress, as couples argued about how much money and to which side of the family it should be sent to (Woelz-Stirling et al.).

\section{Gendered Experiences}

For Asian American immigrants and refugees, the migration experience not only fractures the family network but it also disrupts traditional gender roles (Ishii-Kuntz, 2004). Despite many similarities across Asian American families, however, gender role expectations vary based upon the ethnic group of origin and generation in the United States. For instance, Chinese American families, like many other Asian American families, often have a strong collectivist orientation guided by Confucian values, which endorse strict gender roles and expectations (Sue \& Sue, 2008). Filial piety is highly honored, and family relationships are hierarchical in nature (Sue \& Sue). This hierarchy is structured by age and gender (Nghe, Mahalik, \& Lowe, 2003). Males have more authority than females; therefore, husbands and fathers are the heads of the family, and they hold the decision-making power (Sue \& Sue, 2008).

Many changes occur within the family postimmigration, including shift in gender roles and processes. Particularly for men, the skills and occupational experiences from their native country do not necessarily translate to similar positions in the United States. For example, a Korean American man might have been a doctor in Korea; however, after immigrating to the United States, he may have to restart at the bottom of the occupational ladder or abandon his career altogether, due to language or credential barriers. In addition, he may also encounter contradictory Americanized gender norms and racial stereotypes that marginalize him as an emasculated or feminized man (Lui, 2002).

As a result of immigration, men typically experience economic and social loss, while women become either co-providers or the sole providers for their families (Espiritu, 1999; Yee et al., 2006). Asian American women tend to find more job opportunities in the United States than in their native countries (Espiritu, 1999; Qin, 2006). They may enter the workforce by choice or by the need to support their family. While Asian American men tend to hold more traditional values, research shows that Asian American women tend to acculturate faster and adopt more egalitarian beliefs (Dion \& Dion, 2001; Tang \& Dion, 1999). With their new earning power, Asian American women have more say in family decision-making processes, thereby decreasing the men's authority as main breadwinners.

Conflicts often arise as families face the challenge of redefining gender roles, while attempting to maintain traditional patriarchal family structures. Women, in particular, face the added stress of performing household labor and working outside the home. Furthermore, the downward mobility of males often causes marital conflicts that may escalate and increase the risk of marital violence (Bui \& Morash, 1999; Kim, Lau, \& Chang, 2007). All of these factors and cultural changes may be seen as a threat to the hierarchical family structure and the patriarchal position of the male head of household. Consequently, this instability with the added stress and frustration may push Asian American men to attempt to reassert his control over the family through physical violence and marital abuse (Lui, 2002; Lum, 1998; Suarez-Orozco \& Qin, 2006). More research is needed to understand how Asian American men cope with both gender role and racial conflicts. Future studies should also examine 
how Asian American families cope with stress and how to minimize incidences of marital and familial violence.

\section{Domestic Violence}

The most stressful and detrimental aspect of Asian American family life may be violence within the home. Although there are no national data concerning the prevalence of domestic violence within the Asian American community, a study conducted by the Asian Task Force Against Domestic Violence has shed some light on this issue Yoshioka, Dang, Shewmangal, Chan, and Tan (2000). In this study, the researchers sampled Chinese, Cambodian, Korean, South Asian, and Vietnamese in Massachusetts, and they found that $25-38 \%$ of their participants $(\mathrm{N}=607)$ reported knowing a woman who met at least one criteria of domestic abuse (e.g., isolation, physical assaults). On the other hand, $12 \%$ of the respondents indicated that they know a man who is being beaten by his partner. Similarly, when domestic violence occurs, seeking outside intervention is considered shameful and brings dishonor to the family (Kim et al., 2007; Yoshioka et al., 2000). Keeping from losing face, a core traditional cultural value of many Asian ethnic groups, is more about the impact of an individual's behavior on his/her family than about an individual's personal feeling of shame and guilt (Hall \& Eap, 2007). Victims do not seek outside help because they are concerned about the impact of their act on other people in the family. This cultural emphasis also keeps Asian families from seeking professional and public assistance for mental health and family conflict resolution. Two contextual factors contribute to intimate partner violence among Asian American couples (Kim et al., 2007). First, among the most significant stressors related to immigration and acculturation process are social isolation, experiences prior to the immigration such as trauma, and changes in social status as well as gender roles before and after the migration. Second, male superiority and male preference in the culture of the country of origin make it difficult for male spouse to adjust to the redefined gender roles, with the result being that marital conflict is exacerbated.

\section{Strengths, Resiliency, and Acculturation Framework}

Studies of Asian American family strengths remain patchy and is a topic that warrants more scholarly attention and research in the future. However, a few studies using samples from the country of origin have been conducted that this study will draw upon. Stinnett and DeFrain (1985) identified six American family strengths: appreciation and affection; commitment; positive communication; enjoyable time together; spiritual well-being; and the effective management of stress and crisis. Olson and DeFrain (2003) compared Olson's model of three major qualities with their model of six characteristics and found that they fit well together. Olson's cohesion was represented by DeFrain and Stinnett's commitment and time together. Olson's adaptability fit closely to their family's ability to cope with crisis and spiritual well-being. Olson's communication was equivalent to DeFrain and Stinnett's positive communication and appreciation and affection.

Cross-cultural studies continually enhance the ever-evolving family strengths model (DeFrain \& Asay, 2007; DeFrain \& Stinett, 2002). For example, Casas (1979) conducted a study of Latin American families and concluded that love, understanding, mutual respect, family togetherness, and communication were the major qualities of strong Latin American families. Xie, DeFrain, Meredith, and Combs (1996) found that families in China perceived that a sense of harmony was part of family strengths. A sense of harmony was defined as having a sense of family, having commitment to the family, enjoying each other's company, getting along, and being willing to compromise and forgive. Medora, Larson, and Paml (2000) conducted a similar study in India and identified five of the six aforementioned strengths by Stinnett and DeFrain (1985). Besides those five, three other strengths were revealed. They were a sense of harmony, a 
feeling of support and overall well-being, and a feeling of cooperation and dependability.

A limited number of Asian American Family Strengths studies have found the common strengths that are revealed in the samples of the countries of origin and, in addition, these studies have revealed salient strengths unique to Asian American families. Ishii-Kuntz (1997a) proposed that three central family strengths of Chinese American families are cultural continuity (despite early immigrant adversities); the absorption of extended family members; and the financial contribution of women. The major family strengths of Japanese American family are strong family solidarity (despite historical experiences), strong feelings of obligation and commitment towards parents, and tolerance toward family diversity (Ishii-Kuntz, 1997b). Xie, Xia, and Zhou (2004) conducted a mixed method study of Chinese Americans about their family strengths and acculturation stress. Their qualitative study revealed a model of five major themes related to family strengths and three themes related to acculturation stress. Themes germane to family strengths included: family support leading to achieving a renewed sense of family; contextual support from friends and community; communication among family members; spiritual well-being; and balancing host and heritage cultures. Themes associated with acculturative stress were: language barriers, loneliness, and loss of social status and identity at the early stage of immigration. Measures were developed based on this new model and used in a subsequent survey (Xia, Xie, \& Zhou, 2005). A Confirmative Factor Analysis (CPA) indicated that the survey data supported the Chinese American family strengths model.

Many immigrants in their process to adapt to the culture strive to reestablish their social groups through associations or church organizations. One example would be the pivotal role Korean churches play in Korean immigrants' adjustment to the new culture (Choi, 1997). According to Kim (1981), Korean churches serve as a cultural broker between the congregation and other larger social institutions. Therefore, the functions of churches include "the religious need (meaning), the so- cial need (belonging), and the psychological need (comfort)" (Hurh \& Kim, 1990). Coehlo, Yuan, and Ahmed (1980) suggest that the presence of support from people of both the same country of origin and the host culture is likely to facilitate an immigrant's adaptation. Contact with people from the same country reinforces one's sense of self and affinity to the heritage culture, whereas contact with people from the host culture facilitates the entry into the American society.

Kim (1995) identified a process of "stress-adaptation- growth" that many immigrants achieved in a new country provided they had the social support and individual motivation. In this process, an immigrant's identity was no longer monocultural, but bicultural. Bicultural identity was "an identity that conjoins and integrates, rather than separates and divides" (p. 348). It depicts immigrants adopting and balancing the two cultures they live in. Furthermore, research on acculturation and cultural identity has more and more recognized that acculturation is not a static state but a process of negotiation and integration, for example, bidirectional model (Berry, 1980; Ryder, Alden, \& Paulhus, 2000) and the developmental model of Asian identity development by Sue, Mak, and Sue (1998). However, research with Asian American samples need to take into account the social context, as the political realities of Asian Americans are different and the behavioral outcomes (e.g., academic achievements and help seeking) associated with these constructs are different (Bhatia, 2003; Okazaki, Lee, \& Sue, 2007; Tanaca, Ebreo, Linn, \& Morera, 1998).

Despite the challenges and stress Asian American families encounter during their migration experiences in the United States, these families also exhibited strengths and resiliency that ultimately help them reestablish their lives in this country. It is worth noting that what is found in early research about the role of Korean church and the recent research about Chinese American Family strengths shows the enculturation process defined by Kim and Abreu (2001). Korean American and Chinese Americans strengthen their families and community by maintaining and socializing or resocializing 
themselves into their culture heritage while adapting to the new social and cultural environment in the United States. They survive and then thrive by balancing between these two processes (enculturation and acculturation).

\section{Asian American Children}

\section{Redefined Roles}

As part of the immigrant family system, children are also impacted by the changes in the familial, social, political, and economic contexts due to the migration. However, very little research has comprehensively examined the experiences, and particularly, stress in Asian American children. Growing up in the United States, they straddle two different worlds, their minority culture as well as the dominant society (Suarez-Orozco \& Suarez-Orozco, 2002). Asian American youths confront the complex task of identity formation and cultural group affiliation (Suarez-Orozco \& Qin, 2006). Sometimes, they are forced to integrate conflicting values and beliefs, living in an individualistic society while upholding collectivist traditions (Sue \& Sue, 2008). Similar to their parents, Asian American children also face racism and discrimination in their social life.

Specifically, children of newly arrived immigrant and refugee families often find themselves facing many new responsibilities. Because they tend to acculturate and acquire the language faster than their parents, children often become a social and language broker for their parents. Children often encounter situations that they may not be ready or adequately prepared for. They are placed in adult settings, in the center of adult interactions, being exposed to medical, financial, and other personal information, and forced to make decisions that might not be appropriate for children (Yee et al., 2006). In the process of carrying out these new roles to help their family, parental power has to be compromised and family dynamics are changed.

Especially for children who are older siblings in their families, in addition to helping parents, they are required to fulfill their responsibilities for helping their younger siblings. For example, "South Asian siblings care for younger siblings and teach them survival skills -personal self-care, domestic skills, or occupational skills" (Yee et al., 2006, p. 76). Moreover, among Vietnamese and Korean American children, the first born and older siblings tend to have higher status within the household, are more involved in disciplining younger siblings, and hold more traditional viewpoints and behaviors similar to the parents (Pyke, 2005). Therefore, the older siblings must act as second parental figures, teaching and disciplining their younger siblings. They often serve as a mediator between parents and younger siblings. More research is needed to understand how these experiences affect Asian American children in general.

\section{Parenting and Parent-Child Relationships}

The immigration process has affected the normal parent-child relationship as presented by several case studies and research on immigrant children (Berrol, 1995; Rumbaut, 1994; Zhou, 1997). First of all, serial migration (Waters, 1997) prevents family members from being united simultaneously. In many situations, parents come to the United States for a lengthy period of time before their children can join them, and thus, strain the parent-child relationship. Second, economic survival in the new land necessitates the father's as well as mother's work force participation. This often results in parents' long absence from home and leaving little time for the supervision of children. Last, immigrant children live in the families where parents do not speak English well, and they are accorded the interpreter and translator positions in the family. This role reversal can decrease parental authority and lead to parental dependence on children (Ngyuen \& Huang, 2007; Zhou, 1997).

Because of language and the school environment, children and their parents tend to acculturate at different speed, a phenomena that led Portes and Rumbaut (1996) to conceptualize the acculturation gaps between immigrant parents and their 
offspring as "generational consonance vs. dissonance." Generational consonance refers to the notion when both parents and children acculturate at the same speed or remained unacculturated, whereas generational dissonance occurs when children acculturate at a faster speed than that of their parents and fail to conform to parental authority. Baumrind $(1971,1991)$ identifies four patterns of parenting styles that describe how parents negotiate the needs of children for both nurturance and limit setting. These four styles of parenting are authoritative parents, who are both demanding and responsive using supportive rather than punitive disciplinary methods; permissive parents, who are more responsive than they are demanding and are lenient and avoid confrontation; authoritarian parents, who are demanding and directive but not responsive, expecting their orders to be followed without clarification; and rejecting-neglecting or disengaged parents, who are neither demanding nor responsive and provide no structure nor support. According to studies with European American samples, the authoritarian parenting style has been found to be associated with lower school achievement. However, this does not hold true with Asian student sample who scored high on the authoritarian style, and yet as a group, achieved the highest GPA (Chao, 1994; Kim \& Chun, 1994).

Some researchers have begun to challenge the aforementioned parenting styles. Chao's (1994) study reveals that Baumrind's (1971) typology does not adequately capture the important features of Chinese child rearing, implying that parents from different cultures may be using other types of effective parenting styles that do not fall under Baumrind's (1971) parenting styles. According to Chao (1994), a different style of parenting typical of Chinese American parents was called "training" - it accentuates the importance of parental supervision in working hard, being self-disciplined, and achieving academic success. Therefore, this type of parenting has acquired an extra component other than the emotional one manifested in praising, hugging, and kissing. This new component includes "an investment, involvement, and support of children."
Another study with Korean American adolescents who have been raised in the "Korean way" reveals that these adolescents consider authoritarian parents to be positive parental figures, and they see this parenting style as appropriate (Kim, 2002). This lends support to the notion of different parenting practices in different cultures. Whereas strict and controlling supervision leads to low academic achievement among White students, it results in positive outcomes for Korean American children's educational success (Kim).

From the perspective of Asian American youth, treating elders with respect, following parents' advice, and fulfilling family obligations are highly valued, more so than their European American counterparts (Fuligni, Tseng, \& Lam, 1999). However, the youth believe that their values and expectations concerning familial obligation are lower than that of their parents (Fuligni et al.). This could be a source of conflict within the parent-child relationship. For instance, highly assimilated Korean American youth reported experiencing greater conflict with their parents who tend to hold more traditional values (Rhee, Chang, \& Rhee, 2003). The conflict could intensify across the different generations, as third generation Asian American youth tend to have a lower sense of familial obligation than their first generation peers (Fuligni et al., 1999). Specifically for Asian American females, inter-generational conflicts are heightened around issues relating to dating and marriage (Chung, 2001). Daughters often reported more tension with their parents for being overly protective and imposing their traditional viewpoints on them (Chung). Overall, contrary to popular belief, having a strong sense of familial obligation and collectivist values did not seem to impede the social development and peer relationships of Asian American youth (Fuligni et al., 1999).

\section{Communication Patterns}

Affectionate and open communication are generally discouraged in Asian culture (Le, Berenbaum, \& Raghavan, 2002; Lowinger \& Kwok, 2001). This includes physical and verbal expres- 
sions of love, anger, and other strong emotions and opinions. The emphasis on restricted communication has its roots in the Asian cultural values of maintaining harmony (Kim \& Kim, 2001), collective interests, and tolerance. Unaffectionate and implicit communication is observed in families with parents who are more traditional and less assimilated to American society (Chung, 2001). This has become less desirable in families with parents who have obtained advanced education and in the families with young adult children.

Research on Chinese families shows that open communication is inversely associated with parent- adolescent conflict (Xia et al., 2(04). Park, Yo, and Tsong (2009) have found the similar association in the study of parents and their adult children in Chinese, Korean, Vietnamese, and Filipino American families, and Asian Indian American families. Their study also found that, even if fathers and sons have different views about cultural values, they can still enjoy a good relationship if they communicate openly and are sensitive to each other's emotional needs. Without open and affectionate communication, conflict increases between fathers and sons, as well as mothers and daughters. Affectionate communication significantly benefits father-daughter relationships when the differences in their cultural values and beliefs are low (Park et al.).

\section{Academic Achievements and Parental Expectations}

As a group, Asian American children have achieved an impressive record of academic success. Studies show that their grade point averages in high school and college are higher, and on an average, they score higher on the Scholastic Aptitude Test (SAT) than other ethnic groups (Sue \& Abe, 1995). They also have a higher percentage of college and post-bachelor degrees compared with other ethnic groups (U.S. Census Bureau, 2009a, 2009b). Specifically, $29.4 \%$ Asian vs. $18.5 \%$ of nonHispanic Whites, $11.5 \%$ of African Americans, $8.7 \%$ of Hispanics, and $8.6 \%$ of Native Americans have received bachelor's degrees (U.S. Census Bureau, 2009a, 2009b). As for post-bachelor's degrees,
20.2\% of Asian, $10.8 \%$ of non-Hispanic Whites, 6.1 $\%$ of African Americans, 3.9\% of Hispanic, and $4.4 \%$ of Native Americans (U.S. Census Bureau, 2009a, 2009b). This record of excellence in academics has to do with the deeply rooted belief in Asian culture that diligence and effort is more indicative of success than intelligence. Chen and Stevenson (1995) found that Asian American 11th graders spent almost $20 \mathrm{~h}$ a week studying, and their EuroAmerican counterparts spent about $14 \mathrm{~h}$ a week. They also devoted more time in other educational activities, such as private tutoring or after-school studies, music, and their ethnic language lessons. In order to concentrate on their studies, they were not encouraged to hold a part-time job, be involved in dating, or perform household chores (Chen \& Stevenson, 1995; Kao, 1995). However, there are variations in educational attainment among different Asian American subgroups. East Asians, such as Chinese $(25.7 \%)$, Japanese $(31.6 \%)$, and Koreans $(33.7 \%)$, are more likely to have earned a Bachelor's degree than Southeast Asians, such as Cambodian (10.7\%), Hmong (11.2\%), Laotian (8.7\%), and Vietnamese $(18.1 \%)$, with the exception of Filipinos (38.9\%) (U.S. Census Bureau, 2009a, 2009b).

Besides hard work, studies also show that parental involvement is another key factor. Parental involvement includes providing encouragement, support, and direct instruction at home and maintaining open communications with the school. Studies showed that, when compared to their counterparts in other ethnic groups, Asian American parents consistently have higher educational expectations for their offspring in terms of school performance, college choices, college and postgraduate degrees, and the appropriate amount of time and effort their children spend on studies (Chen \& Stevenson, 1995; Kao, 1995; Spera, Wentzel, \& Matto, 2009).

Asian Americans strongly believe education is the key to upward social mobility. Sorenson (1994) believes that Koreans consider education, indicative of social status, to have "intrinsic worth". Parents place high expectations for their children's academic success. The high degree of parental involvement and its positive outcome in terms of educational achievement are embedded in the Ko- 
rean society. When they immigrate to the United States, they bring along their cultural expectations on education. Kim (2002) shows that parental expectations, communication between parents and children, and parents' English proficiency were significant factors in predicting children's academic achievement.

\section{Older Asian American Immigrants and Intergenerational Relationships}

The number of Asian American seniors is burgeoning. This group is the fastest growing minority senior group, with an increase of $114 \%$ between 1980 and 1990, and an increase of $64.4 \%$ (0.81-1.34 million) between 2000 and 2009 (U.S. Census Bureau, 2011). In 1990, the four largest sending countries of senior immigrants were Philippines, China, Korea, and Vietnam, with a total of 14,481 , or $30 \%$ of all senior immigrants who came to the United States (U.S. Immigration \& Naturalization, 1991). Senior Asian immigrants are far from a homogeneous group. Min (1998) conceptualized Asian seniors as being members of two distinct groups-the "invited senior" and the "immigrated senior." The first group are invited to immigrate to the United States by their adult children residing in the United States and are themselves senior upon their arrival. The second group immigrate to the US with their families as adults and reach old age later. Therefore, the first group tend to depend on their children and the US government for their living, whereas the second group achieve independence through their work history. The language proficiency levels and their acculturation degrees vary between these two groups. As aforementioned earlier, immigration history varies among ethnic groups. A significant number of Korean immigrants came to the United States after the 1965 Immigration Act, and therefore, many of the Korean elderly are "invited elderly."

Asian American families have been under the influence of Confucianism through the millennia. This philosophy emphasizes social and family harmony and adherence to the family hierarchy (Ho, 1981; Hsu, 1985). Inherent in Confucianism is the notion of filial piety which conveys respect and obligation to aging parents, honoring the family name, and emphasis on group harmony (Wong, 1998). Filial piety entails authority, the power hierarchy, and family lineage (Chow, 1996). Asian families are described as highly cohesive, partially due to a high cultural emphasis on harmony and mutual obligations and low value on overt conflicts because obedience and respect for elders are valued. One practice of subordinating oneself to the larger social group is seen in the way Asians write their names. The family name, being more important, precedes the personal name (Wong \& Lai, 2000).

One manifestation of filial piety is in the formation of the extended family in which three generations co-reside, and mutual exchange of services is available. Min (2006) reported that $15 \%$ of Asian American families are multi-generational, with Filipino families being the highest $(22 \%)$, followed by Vietnamese $16 \%$, Chinese, $15 \%$, Korean $10 \%$, and Japanese $5 \%$, the lowest. Other studies found that separate residence is becoming more common among middle-class Chinese immigrant families (Kritz, Gurak, \& Chen, 2000; Lan, 2002; Lee \& Angel, 2002). Factors that influenced independent living include the degree of integration, English language proficiency, length of US residence, citizenship status, ethnic group membership, health status, available resources, and available choices (Forsyth et al., 2009; Kritz et al., 2000; Liang, Brown, Krause, Ofstedal, \& Bennett, 2005). Overall, senior Japanese were found to be more likely to maintain independent households when they could live with their spouses. Chinese, Filipino, Korean, and Asian Indian were found less likely than Japanese to live independently because they had a shorter length of stay in the US, were later generations rather than the first generation, and maintained a higher level of home cultural values (Phua, Kaufman, \& Park. 2001). Compared with European American families, coresidency of older parents and adult children in Asian American families is, in general, a cultural practice rather than a result of economic constraints, e.g., adult children moving back to live with their parents.

However, acculturation has an impact on senior immigrants' living arrangements. Because of 
the high employment rate among Asian immigrant wives, they are more acculturated to the main culture in which the primary relationship is couple-centered. The traditional partrilineal family in which parents and married sons are emphasized through co-residence is now giving way to neolineal family. According to the 1980 census, 75\% of Korean seniors lived with their adult children; by the 1990 census, $57 \%$ still practiced coresidency with their children, and this number is expected to go down to $50 \%$ in 2000 (Yoo \& Sung, 1997). However, contact between generations is frequent. Kim and $\operatorname{Kim}$ (2001) found that $67-75 \%$ of adult children called their parents once a week or more. Research shows that senior Asian immigrants are more likely to live with their extended families than nonHispanic White immigrants (Wilmoth, 2001).

Results from studies of living arrangements and seniors' emotional health status are divided. Osako and Lui (1986) found that Japanese American senior parents who coresided with their adult children reported a similar degree of loneliness as those who maintained in a separate household. In another study, Kim and Kim (2001) found that the invited Korean senior parents did not feel a sense of belonging in their adult children's family. Some of them felt they were neglected and slighted. Mui and Burnette (1994) revealed that elderly who maintained a separate residence had better physical and functional health than those who lived with family members. However, those who lived independently also reported a higher degree of depression, loneliness, and social isolation than the latter.

As to variations among East Asian elderly and reciprocity between seniors and their adult children, Ishii-Kuntz (1997c) found in her study that Korean immigrant elderly were more likely to receive financial aid, services, and emotional support from their adult children compared to their Chinese and Japanese counterparts. In the same study, Korean adult children were younger than their Chinese and Japanese counterparts and were more likely to have minor offspring that needed the care of the senior. Therefore, a reciprocal care relationship developed between these seniors and their adult children. This was consistent with what
Lee, Netzer, and, Coward (1994) found that elderly parents who provide assistance to their adult children in such areas as child care are more likely to receive support in return. Other studies found that elderly, upon entrance to the United States, instead of being care recipients, were integrated into the family and contributed to family care and support. Many Korean seniors worked in their adult children's business or assisted their children by providing care to the grandchildren and taking care of household chores (Min, 1998). Treas and Mazumdar (2004) concluded that senior immigrants contributed heavily to their adult children's family by cooking, taking care of grandchildren, and passing cultural values to the younger generation. They were valuable assets in immigrant families. Because of immigrants' working schedule, their children have limited interaction with their parents. These seniors, thus, provided critical supervision and support to their grandchildren (Treas, 2008).

\section{Summary}

The number of Asian American families is on the rise, making it $4.6 \%$ of the total US population. Asian American families are also a diverse group, comprising many different ancestries, cultural variations, and countries of origin. However, there remains a paucity of research focusing on Asian American Families. The media's depiction of them as a Model Minority is doing a disservice to this population group. Because of this stereotype, many issues and challenges that this group encounters may not gain adequate attention. Some of these issues include acculturative stress, intimate partner violence, lack of a social support network, and intergenerational relationships and mental and health of all ages. Like other immigrant groups, this group experiences discrimination and racism. Yet, Asian American families also exhibit resiliency and strengths during their immigration journey. They are family-oriented, hardworking, and never give up their dreams. They have overcome many obstacles during this process and find the way to embrace their new lives in the United States. 
Research on Asian American families remains sketchy, although it has been steadily growing (Fang et al., 2008). Many fields (population studies, anthropology, psychology, public health, social work, sociology, and family studies) have all contributed to the new understanding of this population. However, the focus has been on the acculturation process and its related stress, ethnic identity development, child and adolescent development, parenting practice, and elderly living arrangement. Fang et al. have done a nice review of studies on Asian Americans from 1992 to 2006 and propose that future research on Asian American family experiences should be conceptualized and interpreted in its relevant cultural framework rather than in alignment with norms. In our review of literature, we conclude that research is needed that focuses on gendered experiences of adolescent boys and girls (boys in particular), marriage and partner relationships, and the mental health of Asian American elderly. To examine the social, cultural, and political contexts, and their mutual influences, Asian American family research can utilize mixed method designs and the wide variety of data analysis strategies that are available today. For example, research should examine how the cultural and media contexts moderate the association between developmental outcomes and parent-adolescent communication. Research is also needed to understand how the changes in the family system (role expectations, boundaries, patterns of communication, etc.) are associated with the adjustment of Asian American family members. To advance the understanding of Asian American families, research should also examine families as units or systems. Current research neglects this systemic focus in favor of emphasizing the experiences of the individuals within Asian American families.

\section{References}

American Association of Retired Persons (AARP). (2001). In the middle: A report on multicultural boomers coping with family and aging issues. Retrieved on July 1, 2010, from http:// assets.aarp.org/rgcenter/il/in the middle.pdf

Baumrind, D. (1971). Current patterns of parental authority. Developmental Psychology Monographs, 41, 1-103.
Baumrind, D. (1991). Parenting styles and adolescent development. In J. Brooks-Gunn, R. Lerner, \& A. C. Peterson (Eds.), Encyclopedia of adolescence. New York: Garland.

Bhatia, S. (2003). Is "integration" the developmental end goal for all immigrants? Redefining "acculturation strategies" from a genetic-dramatistic perspective. In I. E. Josephs (Ed.), Dialogicality in development (pp. 198-216). Westport, CT: Praeger/Greenwood.

Berrol, S. C. (1995). Growing up American: Immigrant children in America, then and now. New York: Twayne.

Berry, J. W. (1980). Acculturation as varieties of adaptation. In A. M. Padilla (Ed.), Acculturation: Theory, models, and some new findings (pp. 9-25). Boulder, CO: Westview Press.

Berry, J. W. (2001). A psychology of immigration. Journal of Social Issues, 57(1), 615-631.

Blair, R. G. (2000). Risk factors associated with PTSD and major depression among Cambodian refugees in Utah. Health $\mathcal{E}$ Social Work, 25, 23-30.

Bui, H. N., \& Morash, M. (1999). Domestic violence in the Vietnamese immigrant community. Violence Against Women, 5, 769-795.

Bush, K. R., Bohon, S. A., \& Kim, H. (2009). Stress and coping among immigrant families. In S. J. Price \& C. Price (Eds.), Families and change: Coping with stressful events and transitions (4th ed., pp. 285-310). Thousand Oaks: Sage.

Casas, C. E. (1979). Relationship patterns of strong families in Latin America. Unpublished master's thesis, University of Nebraska, Lincoln.

Chan, S. (1991). Asian Americans: An interpretive history. New York: Twayne Publishers.

Chao, R. K. (1994). Beyond parental control and authoritarian parenting style: Understanding Chinese parenting through the cultural notion of training. Child Development, 65, 1111-1119.

Chen, C., \& Stevenson, H. W. (1995). Motivation and mathematics achievement: A comparative study of Asian-American, Caucasian-American, and East Asian high school students. Child Development, 66(4), 1215-1234.

Choi, G. (1997). Acculturative stress, social support, and depression in Korean American families. Journal of Family Social Work, 2(1), 81-97.

Chow, N. W. S. (1996). Filial piety in Asian Chinese communities. Hong Kong Journal of Gerontology, 10, 115-117.

Chung, R. C. Y., \& Bemak, F. (2006). Counseling Americans of Southeast Asian descent: The impact of refugee experience. In C. C. Lee (Ed.), Multicultural issues in counseling: New approaches to diversity (3rd ed., pp. 151-170). Alexandria, VA: American Association for Counseling and Development.

Chung, R. H. G. (2001). Gender, ethnicity, and acculturation in intergenerational conflict of Asian American college students. Cultural Diversity \& Ethnicity Minority Psychology, 7, 376-386.

Coehlo, G. V., Yuan, Y. T., \& Ahmed, P. I. (1980), Contempo- 
rary uprooting and collaborative coping: Behavioral and societal responses. In G. V. Coelho. P. I. Ahmed. \& Y. T. Yuan (Eds.). Uprooting and development( pp. 5-17). New York: Plenum. Costigan.

C. L., \& Dokis, D. P. (2006). Relations between parent-child acculturation differences and adjustment within immigrant Chinese families. Child Development, 77, 1252-1267.

DeFrain, J., \& Asay, S. M. (2007). Strong families around the world. Binghamton. NY: The Haworth Press. Inc.

DeFrain, J., \& Stinett, N. (2002). Family strengths. In J. J. Ponzetti (Ed.). International encyclopedia of marriage and family (pp. 637-642). New York: Macmillan.

Dion, K. K., \& Dion, K. L. (2001). Gender and cultural adaptation in families. Journal of Social Issues, 57(3), 511-521.

Espiritu, Y. L. (1999). Gender and labor in Asian immigrant families. American Behavioral Scientist, 42, 628-647.

Fang, S.. McDowell, T., Goldfarb, K., MacDonald, A., Perumbilly, S., \& Gonzalez-Kruger, G. (2008). Viewing the Asian American experience through a culturally centered research lens: Do scholarship in family science and related discipline fall short? Marriage and Family Review, 44(1), 33-51.

Forsyth, A., Greenhouse, E., Wells, N., Maxwell, L., Laquatra, J., Kay, D., et al. (2009). Residential environments for older Americans and their sustainability: From the room to the region. Retrieved on July 1. 2010, from http:/ / www.cals.comell. edu/cals/devsoc/outreach/environment-and-community/upload/ResidentialEnvirons.pdf

Fuligni, A. J., Tseng, V., \& Lam, M. (1999). Attitudes toward family obligations among American adolescents from Asian, Latin, American, and European backgrounds. Child Development, 70(4), 1030-1044.

Gee, G. C., Delva, J., \& Takeuchi, D. T. (2007). Relationships between self-reported unfair treatment and prescription medication use, illicit drug use, and alcohol dependence among Filipino Americans. American Journal of Public Health, 97, 933-940.

Gee, G. C., Spencer, M., Chen, J., Yip, T., \& Takeuchi, D. T. (2007). The association between self-reported racial discrimination and 12-month DSM-IV mental disorders among Asian Americans nationwide. Social Science \& Medicine. 64, 1984-1996.

Hall, G. C. N., \& Eap, S. (2007). Empirically supported therapies for Asian Americans. In F. T. L. Leung, A. G. Inman, A. Ebreo, L. H. Yang, L. Kinoshita, \& M. Fu (Eds.). Handbook of Asian American psychology (pp. 449-467). Thousand Oaks: Sage.

Hinton, D. E., Rasmussen, A., Leakhena, N., Pollack, M. H., \& Good, M. (2009). Anger, PTSD, and the nuclear family: A study of Cambodian refugees. Social Science \& Medicine, 69, 1387-1394.

Ho, D. Y. F. (1981). Traditional patterns of socialization in Chinese society. Acta Psychologica Tawanica, 23, 81-95.

Hsu, J. (1985). The Chinese family: Relations, problems and therapy. In W. Tseng \& D. Y. H. Wu (Eds.). Chinese culture and mental health (pp. 95-112). Orlando. FL: Academic.

Hurh, W., \& Kim, K. (1990). Religious participation of Korean immigrants in the United States. Journal for the Scientific Studies of Religion, 29(1), 19-34.

Ishii-Kuntz, M. (1997a). Chinese American families. In M. K. DeGenova (Ed.). Families in cultural context. New York: Mayfield.

Ishii-Kuntz, M. (1997b). Japanese American families. In M. K. DeGenova (Ed.). Families in cultural context. New York: Mayfield.

Ishii-Kuntz, M. (1997c). Intergenerational relationships among Chinese, Japanese, and Korean Americans. Family Relations, 46(1), 23-33.

Ishii-Kuntz, M. (2000). Diversity within Asian American families. In D. H. Demo, K. R. Allen. \& M. A. Fine (Eds.). Handbook of family diversity. New York: Oxford University Press.

Ishii-Kuntz, M. (2004). Asian American families: Diverse history, contemporary trends, and the future. In M. Coleman \& L. H. Ganong (Eds.). Handbook of contemporary families: Considering the past, contemplating the future (pp. 369-384). Thousand Oaks, CA: Sage.

Kao, G. (1995). Asian-Americans as model minorities? A look at their academic performance. American Journal of Education, 103, 121-159.

Kim, B. S. K., \& Abreu, J. M. (2001). Acculturation measurement: Theory, current instruments and future directions. In J. G. Ponterontto, J. M. Casas, L. A. Suzuki, \& C. M. Alexander (Eds.). Handbook of multicultural counseling (2nd ed., pp. 394-424). Thousand Oaks. CA: Sage.

Kim. E. (2002). The relationship between parental involvement and children's educational achievement in the Korean immigrant family. Journal of Comparative Family Studies, 33(4). 529-540.

Kim, I. (1981). New urban immigrants: The Korean community in New York. Princeton. NJ: Princeton University Press.

Kim, I. J., Lau, A. S., \& Chang, D. F. (2007). Family violence among Asian Americans. In F. T. L. Leong, A. G. Inman, A. Ebreo, L. H. Yang, \& M. Fu (Eds.), Handbook of Asian American psychology (pp. 69-86). Thousand Oaks, CA: Sage.

Kim, S., \& Kim, K. C. (2001). Intimacy at a distance, Korean American style: Invited Korean elderly and their married children. In L. Katz (Ed.). Age through ethnic lenses: Caring for the elderly in a multicultural society (pp. 45-58). Lanham, MD: Rowman \& Littlefield.

Kim, U., \& Chun, M. (1994). Educational 'success' of Asian Americans: An indigenous perspective. Applied Behavioral Development, 15, 328-342.

Kim, Y. Y. (1995). Cross-cultural adaptation: An integrative theory. In R. L. Wiseman (Ed.). Intercultural communication theory (pp. 170-193). Thousand Oaks, CA: Sage.

Kritz, M. M., Gurak, D. T., \& Chen, L. (2000). Elderly immigrants: Their composition and living arrangements. Journal of Sociology and Social Welfare, 27, 85-114. 
Lan, P. C. (2002). Subcontracting filial piety: Elder care in ethnic Chinese immigrant families in California. Journal of Family Issues, 23(7), 812-835.

Le, H., Berenbaum, H., \& Raghavan, C. (2002). Culture and alexithymia: Mean levels, correlates, and the role of parental socialization of emotions. Emotion, 2, 341-360.

Lee, G. R., Netzer, J. K., \& Coward, R. T. (1994). Filial responsibility expectations and patterns of intergenerational assistance. Journal of Marriage and Family, 56, 559-565.

Lee, G. Y., \& Angel, R. J. (2002). Living arrangements and supplemental security income use among elderly Asians and Hispanics in the United States: The role of nativity and citizenship. Journal of Ethnic and Migration Studies, 28(3), 553-563.

Lee, L. C., \& Zhan, G. (1998). Psychosocial status of children and youths. In L. C. Lee \& N. W. S. Zane (Eds.). Handbook of Asian American psychology (pp. 137- 164). Thousand Oaks. CA: Sage.

Leong, F. T. L., \& Grand, J. A. (2008). Career and work implications of the model minority myth. In G. Li \& L. Wang (Eds.). Model minority myth revisited: An interdisciplinary approach to demystifying Asian American educational experiences (pp. 91-115). Charlotte. NC: Information Age Publishing.

Leong, K. L., Airriess, C. A., Li, W., Chen, A. C., \& Keith, V. M. (2007). Resilient history and rebuilding a community: The Vietnamese American community in New Orleans East. The Journal of American History, 94,770-779.

Liang, J., Brown, J. W., Krause, N., Ofstedal, M. B., \& Bennett, J. (2005). Health and living arrangements of older Americans: Does marriage matter? Journal of Aging and Health, 17(3), 305-335.

Lo, Y. (2010). The impact of acculturation process on Asian American youth's psychological well-being. Journal of Child and Adolescent Psychiatric Nursing, 23(2), 84-91.

Lowinger, R. J., \& Kwok, H. (2001). Parental overprotection in Asian American children: A psychodynamic clinical perspective. Psychotherapy, 38, 319-330.

Lui, W. M. (2002). Exploring the lives of Asian American men: Racial identity, male role norms, gender role conflict, and prejudicial attitudes. Psychology of Men E Masculinity, 3(2), 107-118.

Lum, J. L. (1998). Family violence. In C. C. Lee \& N. W. S. Zane (Eds.). Handbook of Asian American psychology (pp. 505526). Thousand Oaks. CA: Sage.

Medora, N., Larson, J., \& Parul, B. (2000). East-Indian college student's perceptions of family strengths. Journal of Comparative Family Studies, 31, 407-425.

Mental Health America. (2006). Mental health America attitudinal survey: Americans reveal top stressors, how they cope. Retrieved on July 1, 2010 from http:/ / www.nmha.org/index. cfm?objectid=ABD3DC4E-1372-4D20-C8274399C9476E26

Min, P. G. (1998). Changes and conflicts: Korean immigrant families: New York. Boston: Allyn Bacon.

Min, P. G. (2006). Asian Americans: Contemporary trends and is- sues (2nd ed.). Thousand Oaks: Pine Forge Press.

Mistry, R. S., Benner, A. D., Tan, C. S., \& Kim, S. Y. (2009). Family economic stress and academic wellbeing among Chinese American Youth: The influence of adolescents' perceptions of economic strain. Journal of Family Psychology, 23, 279-290.

Moyerman, D. R., \& Foreman, B. D. (1992). Acculturation and adjustment: A meta-analytic study. Hispanic Journal of Behavioral Sciences, 14(2), 163-200.

Mui, A. C., \& Burnette, J. D. (1994). A comparative profile of frail elderly living alone and those living with others. Journal of Gerontological Social Work, 21, 5-26.

Nghe, L. T., Mahalik, J. R., \& Lowe, S. M. (2003). Influences on Vietnamese men: Examining traditional gender roles, the refugee experience, acculturation, and racism in the United States. Journal of Multicultural Counseling \& Development, 31, 245-261.

Ngyuen, L., \& Huang, L. N. (2007). Understanding Asian American youth development: A social ecological perspective (pp. 67-103). In F. T. L. Leong, A. O. Inman, A. Ebreo, L. H. Yang, \& M. Fu (Eds.). Handbook of Asian American psychology (pp. 69-86). Thousand Oaks, CA: Sage.

Okazaki, S., Lee, R. M., \& Sue, S. (2007). Theoretical and conceptual models: Toward Asian American psychology. In F. T. L. Leong, A .G. Inman, A. Ebreo, L. H. Yang, \& M. Gu (Eds.). Handbook of Asian American psychology (pp. 29-46). Thousand Oaks: Sage.

Olson, D. H., \& DeFrain, J. (2003). Marriage and the family: Intimacy, strengths and diversity. New York: McGraw Hill.

Osako, M. M., \& Lui, W. T. (1986). Intergenerational relations and the aged among Japanese Americans. Research on Aging, 8, 128-155.

Park, Y. S., Vo, L. P., \& Tsong, Y. (2009). Family affection as a protective factor against the negative effects of perceived Asian values gap on the parent-child relationship for Asian American male and female college students. Cultural Diversity and Ethnic Minority Psychology, 15(1), 18-26.

Phua, V. C., Kaufman, G., \& Park, K. S. (2001). Strategic adjustments of elderly Asian Americans: Living arrangements and headship. Journal of Comparative Family Studies, 23, 263-281.

Portes, A., \& Rumbaut, R. G. (1996). Immigrant America. Berkeley, CA: University of California Press.

Pyke, K. (2005). "Generational deserters" and "blacksheep": Acculturative differences among siblings in Asian immigrant families. Journal of Family Issues, 26, 491-517.

Qin, D. B. (2006). The role of gender in immigrant children's educational adaptation. Current Issues in Comparative Education, 9(1), 8-19.

Rhee, S., Chang, J., \& Rhee, J. (2003). Acculturation, communication patterns, and self-esteem among Asian American and Caucasian American adolescents. Adolescence. 38(152), 749-768.

Rumbaut, R. G. (1994). The crucible within: Ethnic iden- 
tity, self-esteem, and segmented assimilation among children of immigrants. International Migration Review, 28(4), 748-794.

Ryder, A G., Alden, L. E., \& Paulhus, D. L. (2000). Is acculturation unidimensional or bidimensional? A head-to-head comparison in the prediction of personality, self-identity, and adjustment. Journal of Personality and Social Psychology, 79, 49-65.

Smart, J. F., \& Smart, D. W. (1995). Acculturative stress among Hispanic: Loss and challenge. Journal of Counseling and Development, 73, 390-396.

Sodowsky, G. R., Kwan, K. K., \& Pannu, R. (1995). Ethnic identity of Asians in the United States. In J. G. Ponterotto, J. M. Casas, L. A Suzuki, \& C. M. Alexander (Eds.), Handbook of multicultural counseling (pp. 123-154). Thousand Oaks, CA: Sage.

Sorenson, C. (1994). Success and education in South Korea. Comparative Education Review, 38(1), 10-35.

Spera, C., Wentzel, K. R., \& Matto, H. C. (2009). Parental aspirations for their children's educational attainment: Relations to ethnicity, parental education, children's academic performance, and parental perceptions of school climate. Journal of Youth and Adolescence, 38, 1140-1152.

Stinnett, N., \& DeFrain, J. (1985). Secrets of strong families. Boston: Little, Brown.

Suarez-Orozco, C., \& Qin, D. B. (2006). Gendered perspectives in psychology: Immigrant origin youth. International Migration Review, 40(1), 165-198.

Suarez-Orozco, C., \& Suarez-Orozco, M. M. (2002). Children of immigration. Cambridge, MA: Harvard University Press.

Sue, D., Mak, W., \& Sue, D. W. (1998). Ethnic identity. In L. C. Lee \& N. W. S. Zane (Eds.), Handbook of Asian American psychology (pp. 289-323). Thousand Oaks, CA: Sage.

Sue, D. W., \& Sue, D. (2008). Counseling the culturally diverse: Theory and practice (5th ed.). New York: Wiley.

Sue, S., \& Abe, J. (1995). Predictors of academic achievement among Asian-American and White students (Report No. 8811). College Board Report.

Tanaca, J. S., Ebreo, A., Linn, N., \& Morera, O. F. (1998). Research methods: The construct validity of self-identity and its psychological implications. In L. C. Lee \& N. W. S. Zane (Eds.), Handbook of Asian American psychology (pp. 21-79). Thousand Oaks, CA: Sage.

Tang, M. (2008). Psychological impacts of "model minority" on Asian American. In G. Li \& L. Wang (Eds.), Model minority myth revisited: An interdisciplinary approach to demystifying Asian American educational experiences (pp. 117-132). Charlotte, NC: Information Age Publishing.

Tang, T. N., \& Dion, K. L. (1999). Gender and acculturation in relation to traditionalism: Perceptions of self and parents among Chinese students. Sex Roles, 41, 17-29.

Turner, M. A., Ross, S. L., Bednarz, B. A., Herbig, C., \& Lee, S. J. (2003). Discrimination in metropolitan housing markets: Phase 2-Asians and Pacific Islanders. The Urban Institute.
Retrieved on July 1, 2010, from http://www.huduser.org/ Publications/pdf/phase2_exec_summary.pdf

Treas, J. (2008). Transnational older adults and their families. Family Relations, 57(4), 468-478.

Treas, J., \& Mazumdar, S. (2004). Kinkeeping and caregiving: Contributions of older people in immigrant families. Journal of Comparative Family Studies, 35(1), 105-122.

Census Bureau, U. S. (2000). Current population survey. Washington, DC: Government Printing Office.

U.S. Census Bureau. (2004). Race data. Retrieved on July 1, 2010, from http:/ / www.census.gov/population/www/ socdemo/race/ppl-184.html

U.S. Census Bureau. (2008). 2008 American Community Survey 1-year estimates. Retrieved on July 1 , 2010, from http:/ / factfinder.census.gov/servlet/ DatasetMainPageServlet?_program $=$ ACS

U.S. Census Bureau. (2009a). 2009 American Community Survey 1-year estimates, selected population profile. Retrieved on July 1, 2010, from http:/ / factfinder.census.gov/servlet/ IPCharIterationServlet? ts $=314295455122$

U.S. Census Bureau. (2009b). Current Population Survey. Retrieved on July I, 2010, from http:/ / www.census.gov/ hhes/www/cpstables/032010/hhinc/new01_000.htm

U.S. Census Bureau. (2011). The 2011 statistical abstract. Retrieved on July I, 2010, from http://www.census.gov/compendia/statab/cats/population.html

U.S. Department of Health \& Human Services (DHHS). (2000). Mental health care for Asian Americans and Pacific Islanders. Office of the Surgeon General. Retrieved on July 1, 2010, from http://mentalhealth.samhsa.gov/cre/ch5_introduction.asp

U.S. Immigration \& Naturalization Service. (1991). 1990 statistical yearbook of the immigration and naturalization service. Washington, DC: U.S. Government Printing Office.

Varma, R. (2004). Asian Americans: Achievements mask challenge. Asian Journal of Social Science, 32(2), 290-307.

Waters, M. (1997). Immigrant families at risk: Factors that undermined chances of success. In A. Booth, A C. Crouter, \& N. Landal (Eds.), Immigration and the family: Research and policy on US immigrants (pp. 79-87). New Jersey: Lawrence Erlbaum.

Wilmoth, J. M. (2001). Living arrangements among older immigrants in the United States. The Gerontologist, 41, 228-238.

Woelz-Stirling, N., Manderson, L., Kelaher, M., \& Gordon, S. (2000). Marital conflict and finances among Filipinas in Australia. International Journal of Intercultural Relations, 24,791-805.

Wong, I., \& Lai, P. (2000). Chinese cultural values and performance at job interviews: A Singapore perspective. Business Communication Quarterly, 63(1), 9-22.

Wong, M. G. (1998). The Chinese American family. In C. H. Mindel, R. W. Habenstein, \& R. Wright (Eds.), Ethnic families in America (pp. 284-310). Upper Saddle River, NJ: Prentice Hall. 
Xia, Y., Xie, X., \& Zhou, Z. (2005). Case study: Resiliency in immigrant families. In V. L. Bengtson, A. Acock, K. Allen, P. Dilworth-Anderson, \& D. Klein (Eds.), Sourcebook of family theory and research (pp. 108- 111). Thousand Oaks, CA: Sage.

Xia, Y., Xie, X., Zhou, Z., DeFrain, J., Meredith, W., \& Combs, R. (2004). Chinese adolescents' decisionmaking, parentadolescent communication and relationship. Marriage and Family Review, 35, 119-145.

Xie, X., DeFrain, J., Meredith, W., \& Combs, R. (1996). Family strengths in the People's Republic of China. International Journal of Sociology of the Family. 26(2),17-27.

Xie, X., Xia, Y., \& Zhou, Z. (2004). Strengths and resiliency in Chinese immigrant families. Great Plains Research, 14(2), 203-218.

Yee, B. W. K., DeBarysche, B. D., Yuen, S., Kim, S. Y., \& McCubbins, H. I. (2006). Asian American and Pacific Islander families: Resiliency and life-span socialization in a cultural context. In F. T. L. Leong, A. G. Inman, A. Ebreo, L. H. Yang, \& M. Fu (Eds.), Handbook of Asian American psychology (pp. 69-86). Thousand Oaks, CA: Sage.
Yoo, H. C., Gee, G. C., \& Takeuchi, D. (2009). Discrimination and health among Asian American immigrants: Disentangling racial from language discrimination. Social Science $\mathcal{E}$ Medicine, 68,726-732.

Yoo, S. H., \& Sung, K. T. (1997). Elderly Koreans' tendency to live independently from their adult children: Adaptation to cultural differences in America. Journal of Cross-Cultural Gerontology, 12, 225-244.

Yoshioka, M. R., Dang, Q., Shewmangal, N., Chan, C., \& Tan, C. I. (2000). Asian family violence report: A study of the Chinese. Cambodian. Korean. South Asian and Viemamese communities in Massachusetts, Boston, MA: Asian Task Force Against Domestic Violence.

Zhou, M. (1997). Growing up American: The challenge confronting immigrant children and children of immigrants. Annual Review of Sociology, 23, 63-95.

Zia, H. (2000). Asian American dreams: The emergence of an American people. New York: Farrar, Straus \& Giroux. 